\title{
Isolation and characterization of the promoter of SEPALLATA1-like gene from Platanus acerifolia
}

\author{
S.J. LU ${ }^{1,3}$, S.S. YI ${ }^{1,3}$, L. LIU ${ }^{1,4}$, M.Z. BAO ${ }^{1}$, and G.F. LIU ${ }^{2 *}$ \\ College of Horticulture and Forestry Sciences, Huazhong Agricultural University, Wuhan, 430070, P.R. China \\ Guangzhou Institute of Forestry and Landscape Architecture, Guangzhou, 510405, P.R. China ${ }^{2}$ \\ Tropical Crops Genetic Resources Institute, Chinese Academy of Tropical Agricultural Sciences, \\ Danzhou, Hainan, 571737, P.R. China ${ }^{3}$ \\ District Management Committee of Xi'an North Railway Station, Xi'an, 710021, P.R. China ${ }^{4}$
}

\begin{abstract}
London plane (Platanus acerifolia Wild.) is a famous landscape plant because of its numerous desirable traits except the abundant pollens and seed hairs, which not only pollute the environment but also affect human health. To resolve these problems, we herein isolated and functionally analyzed the promoter of PlacSEP1.1, an orthologous gene of Arabidopsis SEPALLATA1, and investigated the potential usability for cell ablation strategies to engineer reproductive sterility in plants. A 2130 bp 5' upstream region of PlacSEP1.1 was isolated and termed pPlacSEP1.1. Putative motif detections show that there were several types of motifs in pPlacSEP1.1 including core promoter elements, tissue-specific expression regulatory elements, and some negative regulatory elements. $\beta$-Glucuronidase histochemical and quantitative assay showed that pPlacSEP1.1 of all deletions was active in all detected tissues except the shortest deletion D5 in roots. In order to test whether pPlacSEP1.1 could be used for London plane sterility breeding with a cytotoxic gene Barnase, the pPlacSEP1.1::Barnase and pPlacSEP1.1::Barnase-mic35S-Barstar vectors were constructed and transformed into tobacco. The pPlacSEP1.1::Barnase transgenic tobacco showed serious defects with respect to vegetative development and died within a couple of weeks after transplantation. On the other hand, most pPlacSEP1.1::Barnase-mic35S-Barstar transgenic tobacco showed normal vegetative growth and inflorescence, and flower development prevented phenotype.
\end{abstract}

Additional key words: Agrobacterium mediated transformation, Arabidopsis thaliana, cytotoxic gene Barnase, London plane, Nicotiana tabacum, pollution, sterility.

\section{Introduction}

London plane (Platanus acerifolia Wild.) is a famous landscape plant and known as 'the king of street trees' because of its numerous desirable traits, such as rapid growth, excellent shading capability, strong stress resistance, wide adaptation, etc. It is widely used as a roadside and parkland tree in cities throughout the temperate and subtropical regions. But it has a few unfavourable characteristics in urban use, most notably is the abundant pollens shed by mature male flowers in spring which cause pollen allergy and resulted in pollinosis and asthma (Asturias et al. 2002, Enrique et al. 2002). Moreover, the dispersing achenes with numerous stiff hairs released from spring to early summer not only pollute the environment but also cause serious damage to human health. In order to resolve these problems, breeding non-flowering or fruitless cultivars by engineered sterility is imperative.

The genetic engineering research showed that there are a variety of techniques being utilized to genetically engineer reproductive sterility in plants. Techniques currently under development include gene suppression, dominant negative mutants (DNMs), and cell ablation (Skinner et al. 2000). Gene suppression strategies include antisense suppression, co-suppression, and RNA interference. Suppression necessitates the use of gene sequences displaying high similarity to the target gene, and frequently limiting the use of constructs to closely related species. The DNM strategies work at the protein level and theoretically function across more divergent genera, but production of successful DNM transgenes is complex and currently relies on trial and error mutation of conserved amino acids or domains. Cell ablation strategies direct to ablate specific tissues by the controlled expression of a cytotoxic gene. This strategy does not target specific genes and applicable

Submitted 6 December 2019, last revision 26 February 2020, accepted 2 March 2020.

Abbreviations: DNM - dominant negative mutant; GUS - $\beta$-glucuronidase; SEP - SEPALLATA.

Acknowledgements: This work was supported by the National Natural Science Foundation of China (31272206, 31772345).

* Corresponding author; gfliu@mail.hzau.edu.cn 
across the broadest range of genera; however, it requires highly specific floral regulatory elements (i.e., promoters) to direct expression of deleterious gene.

Barnase is a cytotoxic gene encoding an RNase originally from Bacillus amyloliquefaciens (Hartley 1988). Since Mariani et al. (1990, 1992) first developed a male sterility system with the barnase gene regulated by the tapetum-specific promoter TA29, cytotoxic genes in combination with male or female tissue-specific promoters have been exploited for generating reproductive sterility in various species, such as tobacco (Goldman et al. 1994, Beals and Goldberg 1997, Roque et al. 2007), wheat (Block et al. 1997), Brassica napus (Denis et al. 1993, Roque et al. 2007), Kalanchoe blossfeldiana (GarciaSogo et al. 2010), Pelargonium (Garcia-Sogo et al. 2012), cabbage (Lee et al. 2003), Solanum lycopersicon and Arabidopsis thaliana (Roque et al. 2007). Moreover, besides herbaceous plant studied, there have been several reports of barnase gene employed for sterility breeding in trees. For example, the BpFULL1::BARNASE and BPMADS1::BARNASE constructs showed prevented inflorescence development and flowering in birch (Lemmetyinen et al. 2004, Lännenpää et al. 2005). In Populus, TA29::BARNASE transgenic poplar showed stable male sterility but slow field growth (Elorriaga et al. 2014). The PrMC2-barnaseH102E construct was found to efficiently ablate pollen in pine and Eucalyptus spp., and the transgenic plant grew similarly to control trees in all observed attributes except the less pollen (Zhang et al. 2012).

All the studies showed that reproductive tissue-specific promoter is crucial for cell ablation strategies engineering reproductive sterility in plants. Previous studies showed that floral organ development of flowering plants is determined mainly by a group of MADS-box genes. The ABCDE model has been proposed from developmental and molecular studies of Arabidopsis, Antirrhinum, and Petunia (Theissen 2001). According to ABCDE model, AP1-AP1-SEP-SEP, AP1-AP3-PI-SEP, AP3-PI-AG-SEP, and AG-AG-SEP-SEP are required for the formation of sepal, petal, stamen, and carpel, respectively, highlighting the importance of the SEP protein in specifying all four whorls of the flower (Theissen 2001, Krizek and Fletcher 2005). In Arabidopsis, E function genes consist of four SEP genes, i.e., SEP1 (AGL2), SEP2 (AGL4), SEP3 (AGL9), and SEP4 (AGL3)(Ma et al. 1991, Huang et al. 1995, Mandel and Yanofsky 1998, Theissen 2001, Ditta et al. 2004). The four SEP genes are expressed before the onset of $\mathrm{B}$ and $\mathrm{C}$ class gene expression, and SEP1, $S E P 2, S E P 4$ are expressed in all floral whorls, while the expression of $S E P 3$ starts slightly later and is restricted to the inner three whorls, and all SEPs are expressed in the developing ovules (Ma et al. 1991, Flanagan and Ma 1994, Savidge et al. 1995, Mandel and Yanofsky 1998, Pelaz et al. 2000, Ditta et al. 2004). Beside Arabidopsis, the expression of SEP-like genes showed floral-specific in several angiosperm species, including tomato (Uimari et al. 2004), petunia (Ferrario et al. 2003, Van den Bussche et al. 2003, Matsubara et al. 2008), peach (Xu et al. 2008), tobacco (Jang et al. 2002), rice (Cui et al. 2010), oil palm
(Adam et al. 2006), and orchids (Chang et al. 2009). In addition to floral-specific expression, members of SEP gene family are expressed in vegetative tissues, seeds, and fruits (Tzeng et al. 2003, Matsunaga et al. 2004, Xu et al. 2008, Tani et al. 2009, Ireland et al. 2013, Pan et al. 2014, Sun et al. 2014, Cheng et al. 2016).

In London plane, the sequence and expression patterns of SEP-like genes have been described previously (Zhang et al. 2017). There are five SEP genes in London plane, and three of the five SEPs (designated PlacSEP1.1, PlacSEP1.2, and PlacSEP1.3) belong to the SEP1/2/4 clade, while the other two (designated PlacSEP3.1 and PlacSEP3.2) are grouped into the SEP3 clade. All PlacSEPs except for PlacSEP1.1 and PlacSEP1.2 were expressed during the male and female inflorescence initiation stages and throughout the flower and fruit development process, PlacSEP1.1 is just express during subsequent floral and fruit development stages, while PlacSEP1.2 was only detected clearly in female inflorescence at April. PlacSEP1.3 and PlacSEP3.1 were also expressed in vegetative tissues of adult plants, including the shoot apical buds, vegetative subpetiolar buds, and vegetative tissues in mixed flower buds (Zhang et al. 2017). These results showed that the $S E P$ s from London plane may be appropriate candidate for cell ablation strategies engineering reproductive sterility in plants, especially PlacSEP1.1. So, in this study, we isolated and characterized the PlacSEP1.1, and analyzed the potential usability for cell ablation strategies engineering reproductive sterility in plants.

\section{Materials and methods}

Plant materials: Young leaves for DNA extraction were collected from field-grown 50-year-old London plane (Platanus acerifolia Wild.) trees in campus of Huazhong Agricultural University. Tobacco (Nicotiana tabacum L.) cv. Xanthi used for transformation were cultured in the Murashige and Skoog (1962) solid medium at a temperature of $25^{\circ} \mathrm{C}$, a 14-h photoperiod, and an irradiance of $80 \mu \mathrm{mol} \mathrm{m} \mathrm{m}^{-2} \mathrm{~s}^{-1}$.

Isolation and sequence analysis of the PlacSEP1 promoter: London plane genomic DNA was extracted from young leaves, following the cetyltrimethyl ammonium bromide (CTAB) isolation procedure (Li et al. 2007). The 5' upstream region of PlacSEP1.1 was isolated by thermal asymmetric interlaced PCR (Liu et al. 1995, Liu and Huang 1998). According to the cDNA sequence of PlacSEP1.1, three specific primers SP1, SP2 and SP3 were designed (Table 1 Suppl.), and eight arbitrary degenerate (AD) primers, AD1-AD8 ware employed (Lu et al. 2012). The cis-acting regulatory elements in the $5^{\prime}$ upstream region of PlacSEP1.1 were predicted by PLACE (Higo et al. 1999) and PlantCARE (Lescot et al. 2002).

Vector construction: Based on the motifs location, the full length region and five 5'-deletion fragments were selected and amplified for expression vectors construction. Regulatory regions of full length, $1686,1328,1083$, 
862 , and 564 bp upstream from the translation initiation site of PlacSEP1.1 sequences (termed FL, D1, D2, D3, D4, and D5, respectively), were amplified by PCR using forward primers, pPlacSEP1.1FL, pPlacSEP1.1D1, pPlacSEP1.1D2, pPlacSEP1.1D3, pPlacSEP1.1D4, pPlacSEP1.1D5 (Table 1 Suppl.), combined with the same reverse primer pPlacSEP1VR (Table 1 Suppl.), respectively. The 5' end of the forward primers was extended $8 \mathrm{bp}$ to generate a $S p h \mathrm{I}$ digest site and $B g l \mathrm{II}$ in reverse primer, respectively. The amplified products were digested with SphI and BglII, and then ligated into the likewise digested plasmid $p C A M B I A 1303$. The constructed vectors were verified by digestion with SphI and $B g l \mathrm{II}$, and by PCR amplification using primers pPlacSEP1FL, pPlacSEP1D1, pPlacSEP1D2, pPlacSEP1D3, pPlacSEP1D4, pPlacSEP1D5, and 1303R (Table 1 Suppl.), respectively.

In order to test whether pPlacSEP1.1 could be used for London plane sterility breeding with cytotoxic gene Barnase, the pPlacSEP1.1::Barnase-Barstar and pPlacSEP1.1::Barnase-mic35S-Barstar vectors were constructed. Barnase-Barstar was amplified from BpFUL::Barnase plasmid (Lännenpää et al. 2005) by primers BarnaseVF and BarstarVR (Table1 Suppl.) which contained BglII and BstPI digest site. The Barnasemic35S-Barstar construct was built based on the pMD18Barnase-Barstar as follows: The 110 bp length mic35S and Barstar were amplified by 35SVF (contained XbalI digest site), 35SVR and BarstarVF, BarstarVR (Table1 Suppl.), and then built into pMD18-T, respectively. The mic35S was digested with $X b a \mathrm{I}$ and $K p n I$, and then cloned into the pMD18-Barstar plasmid in front of the Barstar gene. Based on the constructed pMD18-Barnse-Barstar, the Barstar was removed (Pst $\mathrm{I} / S p h \mathrm{I})$ and replaced by mic35S-Barstar, giving the Barnase-mic35S-Barstar construct. And then, based on the constructed $F L$ plasmid, $\beta$-glucuronidase (GUS) gene was removed (BglII/BstPI) and replaced with Barnase-Barstar and Barnase-mic35SBarstar, respectively, giving pPlacSEP1.1::Barnase -Barstar and pPlacSEP1.1::Barnase-mic35S-Barstar construct. Subsequently, all the constructed vectors were introduced into the Agrobacterium tumefaciens strain EHA105 by electroporation method (Mahmood et al. 2008).

Plant transformation: Agrobacterium tumefaciens strain EHA105 containing the constructed plasmids were grown at $28^{\circ} \mathrm{C}$ in a Luria-Bertani liquid medium supplemented with $100 \mathrm{mg} \mathrm{dm}^{-3}$ kanamycin. Tobacco leaf disc transformation was performed according to Horsch et al. (1985). The transformants were selected by $25 \mathrm{mg} \mathrm{dm}^{-3}$ hygromycin, then transplanted into soil and grown in greenhouse at normal conditions. The transgenic plants were confirmed by PCR analysis with primers pPlacSEP1ZF, GUSVR, and BarnaseVR (Table 1 Suppl.), respectively.

Histochemical GUS assays: Histochemical localization of GUS activity in FL, D1, D2, D3, D4, and D5 transgenic plants was carried out as described previously (Jefferson et al. 1987). Various tissues of the transgenic and control plants, including young flower, full expanded flower (divided into sepal, petal, stamen, and stigma), young fruit and semi-mature fruit, apical bud, young stem, old stem, young leaf, old leaf, and root, were incubated in $\mathrm{X}$-gluc buffer [50 mM sodium phosphate $\mathrm{pH} 7.0,0.5 \mathrm{mM}$ potassium ferricyanide, $0.5 \mathrm{mM}$ potassium ferrocyanide, $10 \mathrm{mM}$ Na2-EDTA, $0.1 \%(\mathrm{~m} / \mathrm{v})$, Triton $X-100$, and $\left.\left.1 \mathrm{mg} \mathrm{cm}{ }^{-3} X-G l u c\right)\right]$ at $37{ }^{\circ} \mathrm{C}$ for $4-7 \mathrm{~h}$. After staining, the samples were immersed in $70 \%(\mathrm{v} / \mathrm{v})$ ethanol and incubated at room temperature to remove the chlorophyll, and then photographed.

Quantification of GUS activity: For quantitative measurement of GUS activity in transgenic tobacco, we homogenized plant tissues in GUS extraction buffer [50 mM NaH${ }_{2} \mathrm{PO}_{4}, \mathrm{pH} 7.0,10 \mathrm{mM}$ EDTA, $0.1 \%$ (v/v) Triton $X-100,0.1 \%(\mathrm{~m} / \mathrm{v})$, sodium lauryl sarcosine, and $10 \mathrm{mM} \beta$-mercaptoethanol]. The homogenate was centrifuged at $16100 \mathrm{~g}$ and $4^{\circ} \mathrm{C}$ for $10 \mathrm{~min}$, and the GUS activity of the supernatant was assessed according to the method described by Jefferson et al. (1987). Protein content was assessed by the Bradford (1976) method, using bovine serum albumin as a standard. Activitu of GUS was normalized to the protein content in each of the crude extracts and was calculated as picomoles of 4-methylumbelliferone (4-MU) produced per minute, per microgramme of soluble protein.

\section{Results}

Through TAIL-PCR, a 2 130-bp 5' upstream region of PlacSEP1.1 was obtained, termed pPlacSEP1.1. It was submitted to PlantCARE and PLACE to detect putative motifs. The result showed that there were several types of motifs in pPlacSEP1.1 (Table 2 Suppl.), including thirteen core promoter elements for transcription start TATA-box, fifteen CAAT-box, one cis-acting regulatory element A-box, several light response elements, hormone response elements, and stress response elements (Table 2 Suppl.). More important, there were several tissue-specific expression regulatory elements in pPlacSEP1.1, such as GATABOX, MADS-box protein binding motif CArGbox, meristem-specific activation element CCGTCC-box, pollen-specific expression motifs, endosperm-specific expression motifs, seed development related element, xylem development regulatory elements, trichome-specific regulatory elements, etc., and some negative regulatory elements such as WBOXATNPR1, WBOXNTERF3, WRKY71OS, etc. (Table 2 Suppl.).

In order to analyze the regulatory effect of different regions of the pPlacSEP1.1, six constructs with full length (FL) or deletions (D1, D2, D3, D4, and D5) of the pPlacSEP1.1 fused to GUS were generated (Fig. 1) and transformed into tobacco. After selected by hygromycin and confirmed by PCR analysis, 25, 18, 30, 16, 20 and 30 independent tobacco transformants of FL, D1, D2, D3, D4, and D5 were obtained. After a histochemical GUS assay (Fig. 2), we found that, in FL, D1, D2, and D3 transgenic tobacco, GUS staining was observed in apical bud, young 


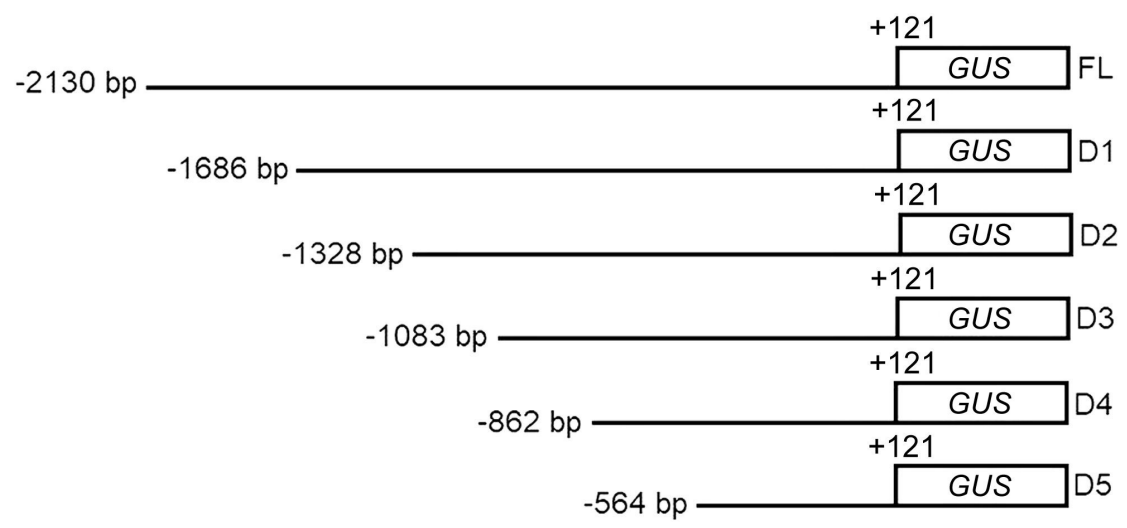

Fig. 1. A schematic representation of expression vectors of the PlacSEP1.1 gene promoter and $\beta$-glucuronidase (GUS) gene constructs.

stem, old stem, young fruit, old fruit, young flower, and sepals of mature flower, and weak staining in young leaf, old leaf, root, and sepals, anther, and stigma of mature flower (Fig. 2). In D4 transgenic tobacco, GUS staining was observed in apical bud, young stem, old stem, young fruit, young flower, and sepals of mature flower, and weak staining in old fruit, young leaf, old leaf, root, and sepal, anther, and stigma of mature flower (Fig. 2). In D5, GUS staining was observed in apical bud, young stem, old stem, and weak staining in the young leaf, old leaf, young fruit, old fruit, young flower and four whorls of mature flower, and no GUS staining was observed in root (Fig. 2).

Quantitative GUS assays were performed to determine the expression strength of different deletions of pPlacSEP1.1 in different tissues of transgenic tobacco by measuring the GUS activity (Fig. 3). The result showed that the FL, D1, D2, D3, and D4 transgenic tobacco had the highest GUS activity in fruit, and followed by apical bud, young stem, old stem, flower, root, old leaf, and young leaf. In flower, sepal had highest GUS activity, followed by petal, carpel, and stamen. Different to FL, D1, D2, D3, and D4 transgenic tobacco, the D5 transgenic tobacco had the highest GUS activity in apical bud and young stem, followed by old stem, sepal, carpel, fruit, petal, stamen, old leaf, and young leaf, and root had a similar GUS staining pattern as wild type.

To test whether pPlacSEP1.1::Barnase-barstar and pPlacSEP1.1::Barnase-mic35S-Barstar can provide a general tool to create flowerless plants, we transformed them into tobacco and generated pPlacSEP1.1::Barnase-barstar and pPlacSEP1.1::Barnase-mic35S-Barstar transgenic tobacco. After selected by hygromycin and confirmed by PCR analysis, one line of pPlacSEP1.1::Barnase-barstar and eight lines of pPlacSEP1.1::Barnase-mic35S-Barstar transgenic tobacco were obtained, respectively. The one line carrying pPlacSEP1.1::Barnase-barstar showed serious defects with respect to vegetative development, for example narrow and pale leaves and strong lateral bud development (Fig. 4A,B), and this line died within a couple of weeks after transplantation. One line carrying pPlacSEP1.1::Barnase-mic35S-Barstar also showed serious defects in vegetative development, for example yellowing and wrinkled leaves (Fig. 4C), and this line also died within a couple weeks after transplantation.
The other seven lines carrying pPlacSEP1.1::Barnasemic35S-Barstar showed normal vegetative development (Fig. 4D,E), however, when the plants began reproductive phase transition, the browning spots appeared on young leaves and expanded gradually (Fig.4F), and then leaves turned yellow and died from tip to base (Fig.4G), but the inflorescence and flower development was inhibited (Fig. $4 G, H$ ).

\section{Discussion}

London plane is one of most important ornamental plant widely used as roadside and parkland tree throughout the temperate and subtropical regions of the world. However, its abundant pollens shed by mature male flowers and the dispersing achenes with numerous stiff hairs released from broken seed balls not only pollute the environment but also cause serious damage to human health. Our major goal was to identify a promoter with high specific activity in reproductive tissues to fuse to cytotoxic gene to targeted ablated reproductive tissues. For this purpose, in this study, based on the previous expression analysis, we isolated the promoter of PlacSEP1.1 from London plane, fused to the $G U S$ gene and transformed in tobacco to analyze its tissues specific activity, and then fused to cytotoxic gene barnase and a modified vector barnase-mic35S-barstar to verify if it could prevent flowering in transgenic tobacco.

In this study, a $2130 \mathrm{bp} 5$ 'upstream region of PlacSEP1.1 was isolated, and the putative cis-element analysis showed that it contains a core promoter element (TATA-box and CAAT-box) and several elements related to flower-, pollen-, and embryo/endosperm-specific development. For example, the CArG-box is the binding site of MADS-box transcription factors (Riechmann et al. 1996, Riechmann and Meyerowitz 1997) and could be the binding site of SOC1-like protein, as observed in Arabidopsis (Lee et al. 2008), the pollen-specific expression motifs GTGANTG10 and POLLEN1LELAT52 are involved in pollen-specific development in tobacco and tomato (Bate and Twell 1998, Rogers et al. 2001), and the motifs Skn1-motif, DOFCOREZM, PROLAMINBOXOSGLUB1, and SEF1MOTIF are related to endosperm/embryo development in rice, wheat, and soybean (Mena et al. 1998, 


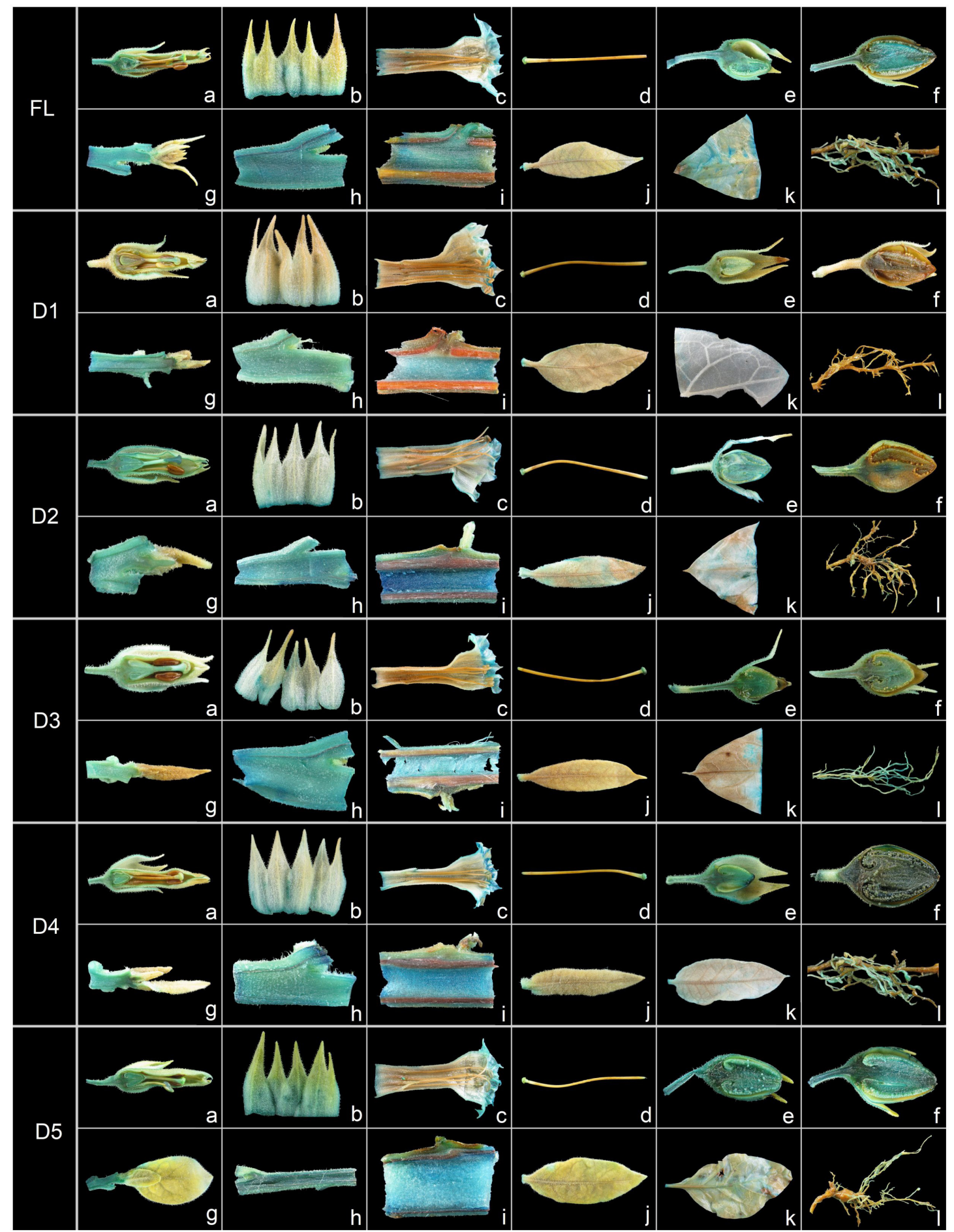

Fig. 2. Histochemical $\beta$-glucuronidase staining in transgenic tobacco lines harboring FL, D1, D2, D3, D4, and D5 constructs: $a$ - young flower, $b$-sepal, $c$ - petal and stamen, $d$ - stigma, $e$ - young fruit, $f$ - semi-mature fruit, $g$ - apical stem, $h$ - young stem, $i$ - old stem, $j$ young leaf, $k$ - old leaf, and $l$ - root.

Washida et al. 1999, Wu et al. 2000, Yoshino et al. 2006). Some light responsive elements, hormone regulation motifs, and negative regulatory motifs were also observed.

Although London plane is transformable (Li et al. 2007), it takes a long time to flower, so we use tobacco as a model system. The histological expression analysis and quantification of GUS activity showed that the transgenic tobacco with full length and all deletions of pPlacSEP1.1 showed high GUS activity in vegetative tissues as well as in reproductive organs. However, previous study showed that PlacSEP1.1 is just expressed during floral and fruit development stages and not in vegetative tissues (Zhang 


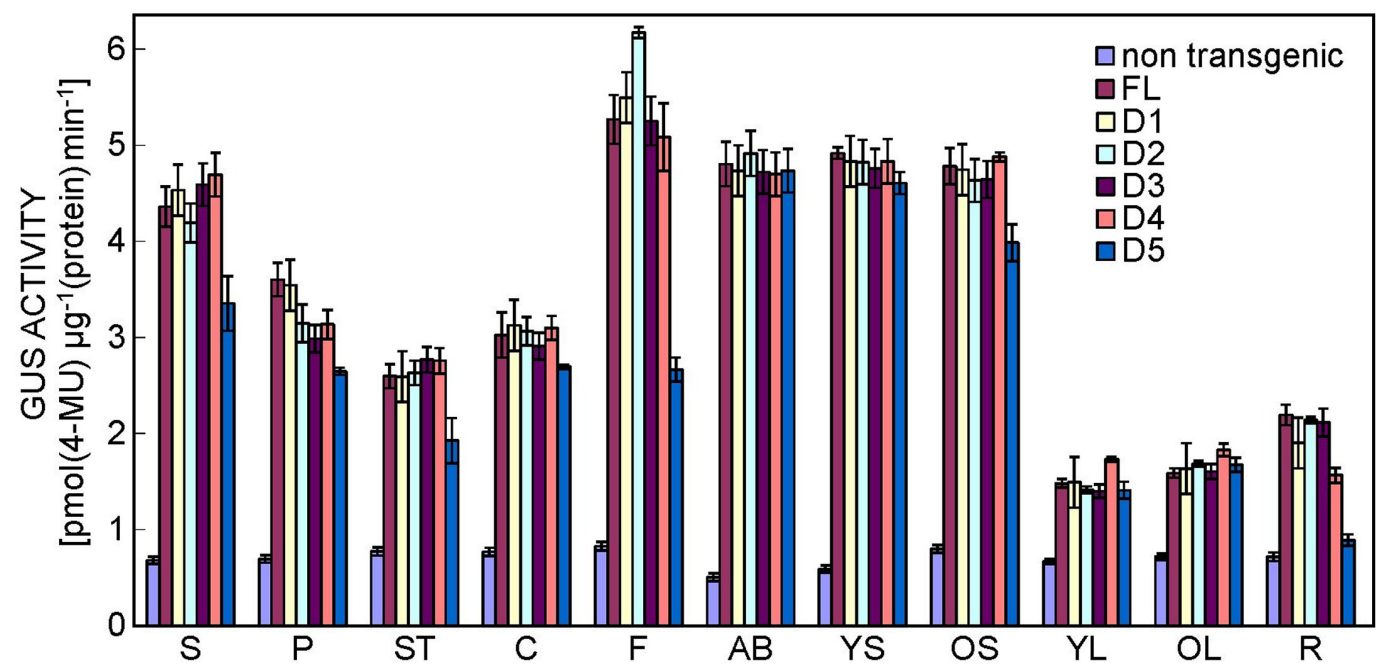

Fig. 3. Fluorometric analysis of $\beta$-glucuronidase (GUS) activity in different tissues of non-transgenic tobacco and transgenic tobacco lines harboring FL, D1, D2, D3, D4, and D5 constructs. S - sepal, P -petal, ST - stamen, C -carpel, F - fruit, AB - apical bud, YS -young stem, OS - old stem, YL - young leaf, OL - old leaf, and R - root.
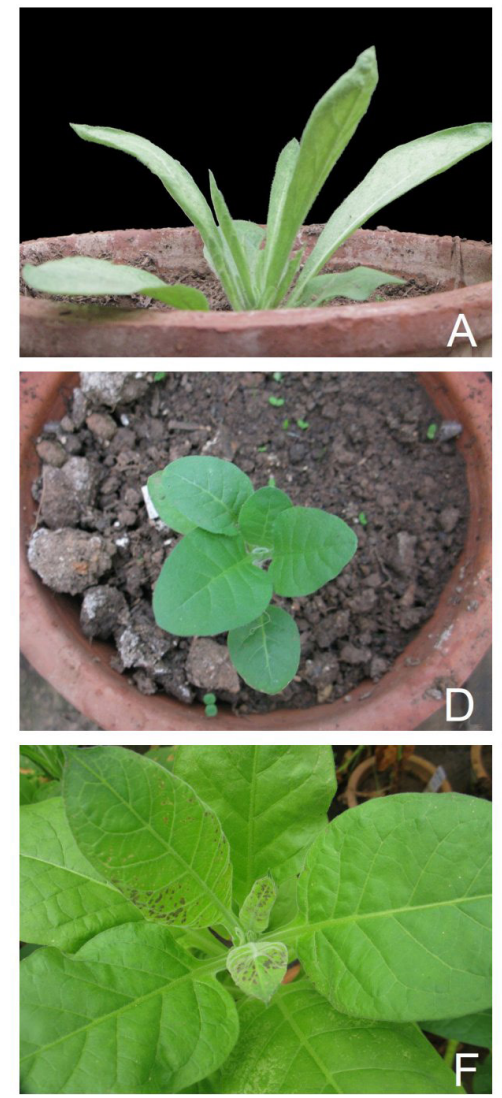
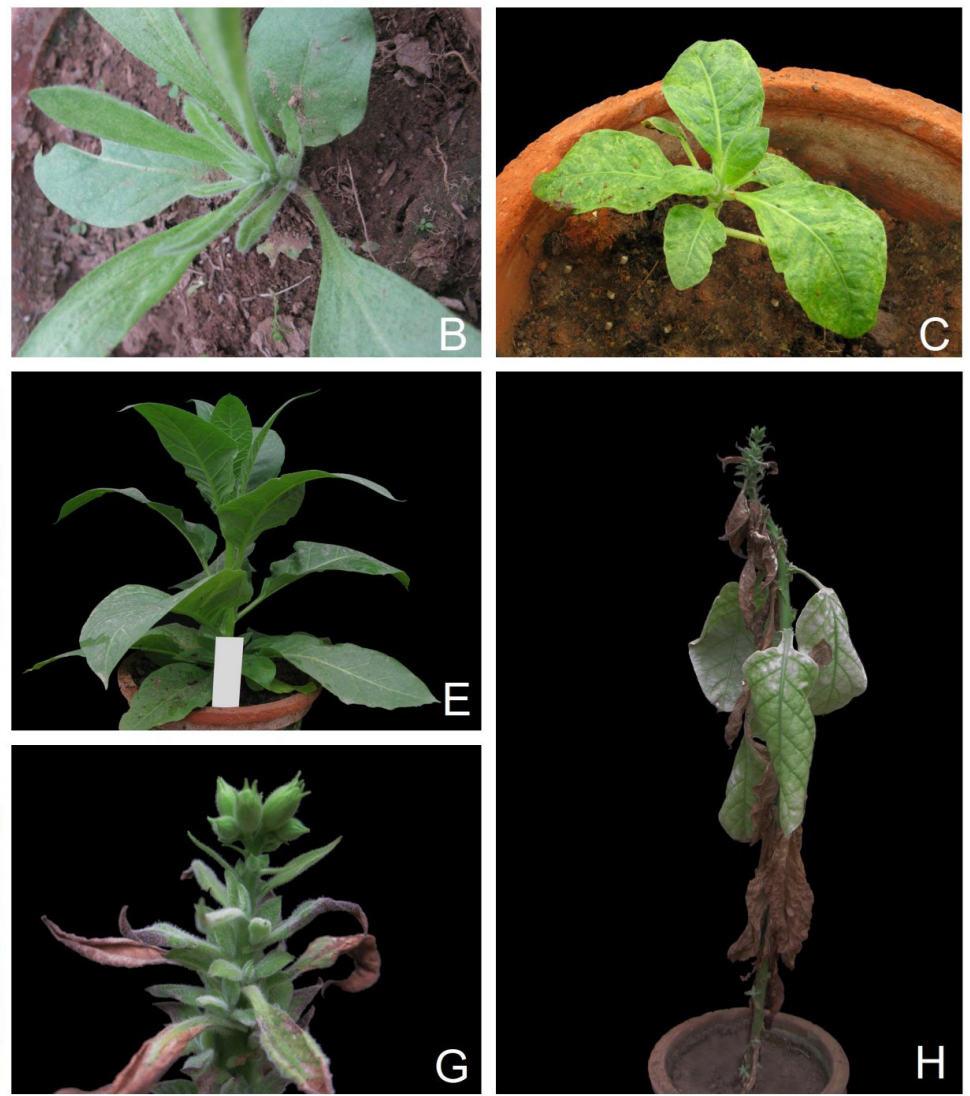

Fig. 4. The phenotype of pPlacSEP1.1::Barnase transgenic tobacco and the prevention of flower development in pPlacSEP1.1::Barnasemic35S-Barstar transgenic tobacco. One line of pPlacSEP1.1::Barnase transgenic tobacco showed serious defects with respect to vegetative development such as narrow and pale leaves $(A)$. Non-flowering line showed dramatic defects in vegetative growth three weeks after transplantation: narrow, pale, and wrinkled leaves and strong lateral bud development $(B)$. One line carrying pPlacSEP1.1::Barnase-mic35S-Barstar also showed serious defects with respect to vegetative development, for example yellowing and wrinkled leaves $(C)$. Seven lines carrying pPlacSEP 1.1::Barnase-mic 35S-Barstar showed normal vegetative development $(D, E)$, these transgenic tobacco lines showed dramatic disorders at the flower formation stage: browning spots which expanded gradually $(F)$, and then turned yellow and the leaf died from tip to base $(G)$, and the inflorescence and flower development were inhibited $(G, H)$. 
et al. 2017). The broader expression pattern conferred by the pPlacSEP1.1 fragment in tobacco model system might be due in part to evolutionary distance or an incomplete promoter region missing key upstream regulatory element. Alternatively, it is possible that post-transcriptional regulation mechanism acts on the native PlacSEP1.1 transcript, but tobacco has no post-transcriptional regulation mechanism and then it contribute to the expression pattern of PlacSEP1.1 in London plane and the GUS in tobacco. It is in accord with the opinion of Hernandez-Garcia and Finer (2014) that the absence of transcription factors require to interact with cis-elements to modify the expression patterns in heterologous systems.

The purpose of this research is to determine whether pPlacSEP1.1 could be used for London plane sterility breeding by driving a cytotoxic gene barnase. However, even though the stable Agrobacterium-mediated transformation of London plane was constructed, we used the tobacco for the detection, because normal London plane tree start flowering after about 6 - 10 years of growth. In this study, we obtained one line of transgenic tobacco which contained the construct pPlaceSEP1.1::Barnase and showed serious defect in vegetative development. It indicted that pPlaceSEP1.1 could drive Barnase slightly expressed in vegetative tissues of young transgenic tobacco. In order to eliminate the cytotoxicity in vegetative tissues, the Barnase-mic35S-Barstar construct was adopted in this research. The phenotype of pPlacSEP1.1::Barnasemic35S-Barstar transgenic tobacco showed that the cytotoxicity in vegetative tissues could be eliminated, and flower formation could be prevented. This may explain by the fact that the cytotoxicity in vegetative tissues which was produced by slight expression of Barnase was completely eliminated by Barstar promoted by mic35S.

The prevention of flower formation and maintenance of normal vegetative growth was the aim of this research. Seven transgenic tobacco lines were non-flowering and showed no phenotypic defects in vegetative growth at the vegetative development stage. However, in the flowering transition stage, the transgenic tobacco showed defects in young leaves. These defects might be caused by the low activation of pPlacSEP1.1 at the vegetative development stage, while at the flowering transition stage, pPlacSEP1.1 activation increased and the Barstar was unable to completely eliminate the cytotoxicity in vegetative tissues. However, whether pPlacSEP1.1::Barnase-mic35SBarstar transgenic woody plants generate this phenotype is still unknown, and additional studies are needed to clarify this.

Taken together, the phenotype of transgenic tobacco containing constructs pPlacSEP1.1::Barnase and pPlacSEP1.1::Barnase-mic35S-Barstar indicated that pPlacSEP1.1 had slight activity in vegetative tissues of transgenic tobacco. It was different to the GUS expression in transgenic tobacco. It may be due to that the GUS expression was affected by post-transcriptional regulation mechanism in tobacco, and the expression of Barnase and Barnase-mic35S-Barstar did not. In conclusion, the pPlacSEP1.1:Barnase-mic35S-Barstar transgenic tobacco showed that pPlacSEP1.1::Barnase-mic35S-
Barstar could prevent tobacco flowering, but more studies are needed to confirm whether it could be used in sterility breeding programs for woody plants.

\section{References}

Adam, H., Jouannic, S., Morcillo, F., Richaud, F., Duval, Y., Tregear, J.W.: MADS box genes in oil palm (Elaeis guineensis): patterns in the evolution of the SQUAMOSA, DEFICIENS, GLOBOSA, AGAMOUS, and SEPALLATA subfamilies. - J. mol. Evol. 62: 15-31, 2006.

Asturias, J.A., Ibarrola, I., Bartolome, B., Ojeda, I., Malet, A., Martinez, A.: Purification and characterization of Pla a 1, a major allergen from Platanus acerifolia pollen. - Allergy 57: 221-227, 2002.

Bate, N., Twel, D.: Functional architecture of a late pollen promoter: pollen-specific transcription is developmentally regulated by multiple stage-specific and co-dependent activator elements. - Plant mol. Biol. 37: 859-869, 1998.

Beals, T.P., Goldberg, R.B.: A novel cell ablation strategy blocks tobacco anther dehiscence. - Plant Cell 9: 1527-1545, 1997.

Block, M.D., Debrouwer, D., Moens, T.: The development of a nuclear male sterility system in wheat. Expression of the barnase gene under the control of tapetum specific promoters. - Theor. appl Genet. 95: 125-131, 1997.

Bradford, M.M.: A rapid and sensitive method for the quantitation of microgram quantities of protein utilizing the principle of protein-dye binding. - Anal Biochem. 72: 248-254, 1976.

Chang, Y.Y., Chiu, Y.F., Wu, J.W., Yang, C.H.: Four orchid (Oncidium Gower Ramsey) AP1/AGL9-like MADS box genes show novel expression patterns and cause different effects on floral transition and formation in Arabidopsis thaliana. - Plant Cell Physiol. 50: 1425-1438, 2009.

Cheng, S.Y., Cheng, J.H., Xu, F., Ye, J.B., Wang, X.H.: Molecular cloning and expression analysis of a putative E class MADSbox gene, GbSEP, from Ginkgo biloba. - J. Anim. Plant Sci. 26: 253-260, 2016.

Cui, R., Han, J., Zhao, S., Su, K., Wu, F., Du, X., Xu, Q., Chong, K., Theissen, G., Meng, Z.: Functional conservation and diversification of class $\mathrm{E}$ floral homeotic genes in rice (Oryza sativa). - Plant J. 61: 767-781, 2010.

Denis, M., Delourme, R., Gourret, J.P., Mariani, C., Renard, M.: Expression of engineered nuclear male sterility in Brassica napus - genetics, morphology, cytology, and sensitivity to temperature. - Plant Physiol. 101: 1295-1304, 1993.

Ditta, G., Pinyopich, A., Robles, P., Pelaz, S., Yanofsky, M.F.: The SEP4 gene of Arabidopsis thaliana functions in floral organ and meristem identity. - Curr. Biol. 14: 1935-1940, 2004.

Elorriaga, E., Meilan, R., Ma, C., Skinner, J.S., Etherington, E., Brunner,A., Strauss, S.H.: A tapetal ablation transgene induces stable male sterility and slows field growth in Populus. - Tree Genet. Genomes 10: 1583-1593, 2014.

Enrique, E., Cistero-Bahima, A., Bartolome, B., Alonso, R., San Miguel-Moncin, M.M., Bartra, J., Martinez, A.: Platanus acerifolia pollinosis and food allergy. - Allergy 57: 351-356, 2002.

Ferrario, S., Immink, R.G., Shchennikova, A., Busscher-Lange, J., Angenent, G.C.: The MADS box gene FBP2 is required for SEPALLATA function in petunia. - Plant Cell 15: 914-925, 2003.

Flanagan, C.A., Ma, H.: Spatially and temporally regulated expression of the MADS-box gene $A G L 2$ in wild-type and mutant Arabidopsis flowers. - Plant mol. Biol. 26: 581-595, 1994. 
Garcia-Sogo, B., Pineda, B., Castelblanque, L., Anton, T., Medina, M., Roque, E., Torresi, C., Beltran, J.P., Moreno, V., Canas, L.A.: Efficient transformation of Kalanchoe blossfeldiana and production of male-sterile plants by engineered anther ablation. - Plant Cell Rep. 29: 61-77, 2010.

Garcia-Sogo, B., Pineda, B., Roque, E., Anton, T., Atares, A., Borja, M., Beltran, J.P., Moreno, V., Canas, L.A.: Production of engineered long-life and male sterile Pelargonium plants. BMC Plant Biol. 12: 156, 2012.

Goldman, M.H., Goldberg, R.B., Mariani, C.: Female sterile tobacco plants are produced by stigma-specific cell ablation. EMBO J. 13: 2976-2984, 1994.

Hartley, R.W.: Barnase and barstar: expression of its cloned inhibitor permits expression of a cloned ribonuclease. - J. mol. Biol. 202: 913-915, 1988

Hernandez-Garcia, C.M., Finer, J.J.: Identification and validation of promoters and cis-acting regulatory elements. - Plant Sci. 217-218: 109-119, 2014.

Higo, K., Ugawa, Y., Iwamoto, M., Korenaga, T.: Plant cis-acting regulatory DNA elements (PLACE) database: 1999. - Nucl. Acid. Res. 27: 297-300, 1999.

Horsch, R.B., Rogers, S.G., Fraley, R.T.: Transgenic plants. Cold Spring Harbour Symp. Quant. Biol. 50: 433-437, 1985.

Huang H., Tudor M., Weiss C.A., Hu Y., Ma H.: The Arabidopsis MADS-box gene $A G L 3$ is widely expressed and encodes a sequence-specific DNA-binding protein. - Plant mol. Biol. 28: 549-567, 1995.

Ireland, H.S., Yao, J.L., Tomes, S., Sutherland, P.W., Nieuwenhuizen, N., Gunaseelan, K., Winz, R.A., David, K.M., Schaffer, R.J.: Apple SEPALLATA1/2-like genes control fruit flesh development and ripening. - Plant J. 73: 1044-1056, 2013.

Jang, S., An, K., Lee, S., An, G.: Characterization of tobacco MADS-box genes involved in floral initiation. - Plant Cell Physiol. 43: 230-238, 2002.

Jefferson, R.A., Kavanagh, T.A., Bevan, M.W.: GUS fusions: beta-glucuronidase as a sensitive and versatile gene fusion marker in higher plants. - EMBO J. 6: 3901-3907, 1987.

Krizek, B.A., Fletcher, J.C.: Molecular mechanisms of flower development: an armchair guide. - Nat. Rev. Genet. 6: 688698, 2005.

Lännenpää, M., Hassinen, M., Ranki, A., Hölttä-Vuori, M., Lemmetyine, J., Keinonen, K., Sopanen, T.: Prevention of flower development in birch and other plants using a BpFULL1::BARNASE construct. - Plant Cell Rep. 24: 69-78, 2005.

Lee, J., Oh, M., Park, H., Lee, I.: SOC1 translocated to the nucleus by interaction with $A G L 24$ directly regulates leafy. Plant J. 55: 832-843, 2008.

Lee, Y.H., Chung, K.H., Kim, H.U., Jin, Y.M., Kim, H.I., Park, B.S.: Induction of male sterile cabbage using a tapetumspecific promoter from Brassica campestris L. ssp. pekinensis. - Plant Cell Rep. 22: 268-273, 2003.

Lemmetyinen, J., Keinonen, K., Sopanen, T.: Prevention of the flowering of a tree, silver birch. - Mol. Breed. 13: 243-249, 2004.

Lescot, M., Dehais, P., Thijs, G., Marchal, K., Moreau, Y., Van de Peer, Y., Rouze, P., Rombauts, S. PlantCARE, a database of plant cis-acting regulatory elements and a portal to tools for in silico analysis of promoter sequences. - Nucl. Acids Res. 30: 325-327, 2002

Li, Z.N., Fang, F., Liu, G.F., Bao, M.Z.: Stable Agrobacteriummediated genetic transformation of London plane tree (Platanus acerifolia Willd.). - Plant Cell Rep. 26: 641-650, 2007.

Liu, Y.G., Huang, N.: Efficient amplification of insert end sequences from bacterial artificial chromosome clones by thermal asymmetric interlaced PCR. - Plant mol. Biol. Rep. 16: $175-181,1998$

Liu, Y.G., Mitsukawa, N., Oosumi, T., Whittier ,R.F.: Efficient isolation and mapping of Arabidopsis thaliana T-DNA insert junctions by thermal asymmetric interlaced PCR. - Plant J. 8 : 457-463, 1995.

Lu, S.J., Li, Z.N., Zhang, J.Q., Yi, S.S., Liu, L., Bao, M.Z., Liu, G.F.: Isolation and expression analysis of a $L E A F Y /$ FLORICAULA homolog and its promoter from London plane (Platanus acerifolia Willd.). - Plant Cell Rep. 31: 1851-1865, 2012.

Ma, H., Yanofsky, M.F., Meyerowitz, E.M.: AGL1-AGL6, an Arabidopsis gene family with similarity to floral homeotic and transcription factor genes. - Genes Dev. 5: 484-495, 1991.

Mahmood, T., Zar, T., Naqvi, S.M.S.: Multiple pulses improve electroporation efficiency in Agrobacterium tumefaciens. Electron J. Biotechn. 11: 1-4, 2008.

Mandel, M., Yanofsky, M.F.: The Arabidopsis AGL9 MADS box gene is expressed in young flower primordia. - Sex Plant Reprod. 11: 22-28, 1998.

Mariani, C., Beuckeleer, M.D., Truettner, J., Leemans, J., Goldberg, R.B.: Induction of male sterility in plants by a chimaeric ribonuclease gene. - Nature 347: 737-741, 1990.

Mariani, C., Gossele, V., Beuckeleer, M.D., Block, M.D., Goldberg, R.B., Greef, W.D., Leemans, J.: A chimaeric ribonuclease-inhibitor gene restores fertility to male sterile plants. - Nature 357: 384-387, 1992.

Matsubara, K., Shimamura, K., Kodama, H., Kokubun, H., Watanabe, H., Basualdo, I.L., Ando, T.: Green corolla segments in a wild Petunia species caused by a mutation in FBP2, a SEPALLATA-like MADS box gene. - Planta 228 401-409, 2008.

Matsunaga, S., Uchida, W., Kejnovsky, E., Isono, E., Moneger, F., Vyskot, B., Kawano, S.: Characterization of two SEPALLATA MADS-box genes from the dioecious plant Silene latifolia. Sex Plant Reprod. 17: 189-193, 2004.

Mena, M., Vicente-Carbajosa, J., Schmidt, R.J., Carbonero, P.: An endosperm-specific DOF protein from barley, highly conserved in wheat, binds to and activates transcription from the prolamin-box of a native B-hordein promoter in barley endosperm. - Plant J. 16: 53-62, 1998.

Murashige, T., Skoog, F.: A revised medium for rapid growth and bio assays with tobacco tissue cultures. - Physiol Plant. 15: 473-497, 1962.

Pan, Z.J., Chen, Y.Y., Du, J.S., Chen, Y.Y., Chung, M.C., Tsai, W.C., Wang, C.N., Chen, H.H.: Flower development of Phalaenopsis orchid involves functionally divergent SEPALLATA-like genes. - New Phytol. 202: 1024-1042, 2014.

Pelaz, S., Ditta, G.S., Baumann, E., Wisman, E., Yanofsky, M.F.: $\mathrm{B}$ and $\mathrm{C}$ floral organ identity functions require SEPALLATA MADS-box genes. - Nature 405: 200-203, 2000.

Riechmann, J.L., Krizek, B.A., Meyerowitz, E.M.: Dimerization specificity of Arabidopsis MADS domain homeotic proteins APETALA1, APETALA3, PISTILLATA, and AGAMOUS. Proc. nat. Acad. Sci. USA 93: 4793-4798, 1996.

Riechmann, J.L., Meyerowitz, E.M.: Determination of floral organ identity by Arabidopsis MADS domain homeotic proteins AP1, AP3, PI, and AG is independent of their DNAbinding specificity. - Mol. Biol. Cell 8: 1243-1259, 1997.

Rogers, H.J., Bate, N., Combe, J., Sullivan, J., Sweetman, J., Swan, C., Lonsdale, D.M., Twell, D.: Functional analysis of cis-regulatory elements within the promoter of the tobacco late pollen gene g10. - Plant mol. Biol. 45: 577-585, 2001.

Roque, E., Gomez, M.D., Ellul, P., Wallbraun, M., Madueno, F., Beltran, J.P., Canas, L.A.: The PsEND1 promoter: a novel 
tool to produce genetically engineered male-sterile plants by early anther ablation. - Plant Cell Rep. 26: 313-325, 2007.

Savidge, B., Rounsley, S.D., Yanofsky, M.F.: Temporal relationship between the transcription of two Arabidopsis MADS box genes and the floral organ identity genes. - Plant Cell 7: 721-733, 1995.

Skinner, J.S., Meilan, R., Brunner, A.M., Strauss, S.H.: Options for genetic engineering of floral sterility in forest trees. - Mol. Biol. Woody Plants 2000: 135-153, 2000.

Sun, W., Huang, W., Li, Z., Song, C., Liu, D., Liu, Y., Hayward, A., Liu, Y., Huang, H., Wang, Y.: Functional and evolutionary analysis of the AP1/SEP/AGL6 superclade of MADS-box genes in the basal eudicot Epimedium sagittatum. - Ann. Bot. 113: 653-668, 2014.

Tani, E., Polidoros, A.N., Flemetakis, E., Stedel, C., Kalloniati, C., Demetriou, K., Katinakis, P., Tsaftaris A.S.: Characterization and expression analysis of AGAMOUS-like, SEEDSTICKlike, and SEPALLATA-like MADS-box genes in peach (Prunus persica) fruit. - Plant Physiol. Biochem. 47: 690-700, 2009.

Theissen, G.: Development of floral organ identity: stories from the MADS house. - Curr. Opin. Plant Biol. 4: 75-85, 2001.

Tzeng, T.Y., Hsiao, C.C., Chi, P.J., Yang, C.H.: Two lily SEPALLATA-like genes cause different effects on floral formation and floral transition in Arabidopsis. - Plant Physiol. 133: 1091-1101, 2003.

Uimari, A., Kotilainen, M., Elomaa, P., Yu, D., Albert, V.A., Teeri, T.H.: Integration of reproductive meristem fates by a SEPALLATA-like MADS-box gene. - Proc. nat. Acad. Sci. USA 101: 15817-15822, 2004.

Van den Bussche, M., Zethof, J., Souer, E., Koes, R., Tornielli, G.B., Pezzotti, M., Ferrario, S., Angenent, G.C., Gerats, T.: Toward the analysis of the petunia MADS box gene family by reverse and forward transposon insertion mutagenesis approaches: B, C, and D floral organ identity functions require SEPALLATA-like MADS box genes in petunia. - Plant Cell 15: 2680-2693, 2003.

Washida, H., Wu, C.Y., Suzuki, A., Yamanouchi, U., Akihama, T., Harada, K., Takaiwa, F.: Identification of cis-regulatory elements required for endosperm expression of the rice storage protein glutelin gene GluB-1. - Plant mol. Biol. 40: 1-12, 1999.

Wu, C., Washida, H., Onodera, Y., Harada, K., Takaiwa, F.: Quantitative nature of the Prolamin-box, ACGT and AACA motifs in a rice glutelin gene promoter: minimal cis-element requirements for endosperm-specific gene expression. - Plant J. 23: 415-421, 2000.

Xu, Y., Zhang, L., Xie, H., Zhang, Y.Q., Oliveira, M.M., Ma, R.C.: Expression analysis and genetic mapping of three SEPALLATA-like genes from peach (Prunus persica (L.) Batsch). - Tree Genet. Genomes 4: 693-703, 2008.

Yoshino, M., Nagamatsu, A., Tsutsumi, K., Kanazawa, A.: The regulatory function of the upstream sequence of the betaconglycinin alpha subunit gene in seed-specific transcription is associated with the presence of the RY sequence. - Genes Genet. Syst. 81: 135-141, 2006.

Zhang, C., Norris-Caneda, K.H., Rottmann, W.H., Gulledge, J.E., Chang, S., Kwan, B.Y., Thomas, A.M., Mandel, L.C., Kothera, R.T., Victor, A.D., Pearson, L., Hinchee, M.A.W.: Control of pollen-mediated gene flow in transgenic trees. Plant Physiol. 159: 1319-1334, 2012.

Zhang, S.S., Lu, S.J., Yi, S.S., Han, H.J., Liu, L., Zhang, J.Q., Bao, M.Z., Liu, G.F.: Functional conservation and divergence of five SEPALLATA-like genes from a basal eudicot tree, Platanus acerifolia. - Planta 245: 439-457, 2017. 